\title{
Isotretinoin Use and Risk of Depression in Acne Vulgaris Patients in Riyadh, Saudi Arabia
}

\author{
Fatimah A. AlGhofaili ${ }^{1}$ \\ 1. Department of Dermatology, College of Medicine, Qassim University, Buraydah, SAU
}

Corresponding author: Fatimah A. AlGhofaili, fatimah-ali-gh@hotmail.com

\begin{abstract}
Background

The association between isotretinoin administration and depression in acne patients remains controversial. We aim to estimate the prevalence of depression among patients with acne vulgaris before and after treatment with isotretinoin in Riyadh, Saudi Arabia.

Methods

This was a prospective study on patients attending the King Khalid University Hospital (KKUH), a tertiary institution, who were prescribed isotretinoin for the treatment of acne vulgaris for the first time. The Beck Depression Inventory (BDI) was used to screen for depressive symptoms.
\end{abstract}

Results

A total of 179 patients were included in the study. The patients were then divided into two groups based on the treatment modality that they received: one group taking isotretinoin and the other treatment group who used other medications, including Retin-A (tretinoin) and Tazorac (tazarotene). A total of 119 patients were in the isotretinoin group with $91.6 \%, 2.5 \%, 1.7 \%$, and $3.4 \%$ of those patients having a normal mood, mild depression, moderate depression, and severe depression scores before starting isotretinoin treatment, respectively. After three months of treatment, $94.1 \%, 1.7 \%, 0.8 \%$, and $2.5 \%$ of patients had normal mood, mild depression, moderate depression, and severe depression, respectively. Meanwhile, after six months of treatment, $95.8 \%, 0.8 \%, 0 \%$, and $1.7 \%$ of patients had normal mood, mild depression, moderate depression, and severe depression, respectively. The mean BDI score at the baseline was $3.31 \pm 6.98$ for isotretinoin and $3.17 \pm 6.27$ for other treatments. Compared to the baseline, patients using the isotretinoin showed a significant reduction in depression scores at three months $(2.64 \pm 6.17$; p-value $<0.001)$, six months $(1.99 \pm$ 5.08; $\mathrm{p}$-value $<0.001$ ), and across all follow-up points ( $\mathrm{p}$-value $<0.001$ ). Similar results were also estimated for the other treatment group, including Retin-A (tretinoin), adapalene, benzoyl peroxide, and doxycycline; however, no significant difference was noticed between the two groups $(\mathrm{p}$-value $=0.885)$.

Review began 02/12/2021 Review ended 02/18/2021 Published 03/03/2021

\section{๑) Copyright 2021}

AlGhofaili. This is an open access article distributed under the terms of the Creative Commons Attribution License CC-BY 4.0., which permits unrestricted use, distribution, and reproduction in any medium, provided the original author and source are credited.
Conclusion

Isotretinoin treatment for acne does not appear to be associated with a statistically significant increased risk of depression in our population. Therefore, more studies are needed to understand this reflection in Saudi Arabia.

Categories: Dermatology, Psychiatry, Epidemiology/Public Health

Keywords: depression, isotretinoin, acne vulgaris, management, beck depression inventory (bdi)

\section{Introduction}

Acne vulgaris is recognized as an inflammatory disorder that affects the pilosebaceous units in the neck, chest, back, and face [1]. Evidence also shows that it has pleomorphic characteristics as it can be found as an inflammatory (recognized as pustules, nodules, or papules) or a non-inflammatory lesion (recognized as closed or open comedones) [2]. Acne vulgaris is a common condition in adolescence and is considered the most common skin disorder, with an estimated prevalence rate of 70\% - 87\% [3]. The condition has a significant impact on the affected patient and may reduce their quality of life. Such an effect can be associated with social and psychological disorders, such as depression, social phobia, low self-esteem, anxiety, and suicidal thoughts [4-5]. Besides, the economic burden is also significant as evidence shows that more than one billion dollars are spent annually on treating the condition and around 100 million dollars are being spent on acne-related products within the United States [6].

Treatment of acne vulgaris is dependent on the severity and morphology of the condition. Topical retinoids are used for mild cases, while systemic regimens that involve hormonal therapy, antibiotics, and oral 
retinoids are used for moderate cases. In addition, isotretinoin is the drug of choice and the most effective therapy in severe and resistant cases [1-2, 5-6]. It is a 13-cis-retinoic acid vitamin A-derivative that acts on all of the four phases of acne development [2, 7-8]. A previous meta-analysis showed that around $85 \%$ of the included patients were cured of acne after an average use of isotretinoin for four months [9]. However, many adverse events have been reported. These include skin, mouth, and nose dryness, sun sensitivity, increased levels of serum cholesterol, suicidal ideations, and depression [10].

The rate for depression after isotretinoin administration is variable and ranges between $1 \%$ and $11 \%$ [11]. However, this side effect may fade away with acne improvement. On the other hand, evidence shows that isotretinoin systemic administration is directly correlated with developing depression [12]. This was supported by previous experimental investigations which claimed that the drug plays a role in the mechanism of depression through a direct effect on the central nervous system [13]. Other researchers said that such evidence should not be counted on as a factor [12]. Although many studies have investigated the association between isotretinoin administration and depression among acne vulgaris patients, little evidence could be found regarding patients from Saudi Arabia. Consequently, we aimed to conduct this study to investigate the correlation in our Saudi population.

\section{Materials And Methods \\ Sample size and data collection}

This was a prospective study of 179 randomly selected new patients attending a tertiary center, King Khalid University Hospital (KKUH) who received treatment for acne vulgaris. Patients were divided into two groups based on the treatment received: the isotretinoin group and the second group using other treatments, including Retin-A (tretinoin) and Tazorac (tazarotene). Written informed consent was obtained from the study participants. An institutional review board approval was also obtained to conduct the study. We included patients who suffered from acne vulgaris and had been receiving isotretinoin or other treatment modalities for up to six months. Patients' baseline characteristics and demographics were collected. Moreover, patients were asked if they developed any depression symptoms or not and the severity of these symptoms was assessed. Patients were divided into two groups based on the treatment modality that they received. Similar to previous studies, depression severity was measured in participants after three and six months of isotretinoin use using the Beck Depression Inventory (BDI) (1 - 10: normal; 11 - 16: mild depression; 17 - 20: borderline clinical depression; 21 - 30: moderate depression; 31 - 40: severe depression; and > 40: extreme depression) [14]. Patients were excluded if they did not fulfill the previous criteria or did not administer isotretinoin for the specified period. For patients in the isotretinoin group, oral isotretinoin was administered at a standard cumulative dose of $150 \mathrm{mg} / \mathrm{kg}$ as a daily dose of about $0.5 \mathrm{mg} / \mathrm{kg}$.

\section{Statistical analysis}

All analyses were done using the Statistical Package for Social Sciences (SPSS), version 26 (IBM SPSS Statistics for Windows, Armonk, NY), and a p-value < 0.05 was considered significant for all tests. Continuous variables were represented as means and standard deviation, using skewness and Kurtosis tests to evaluate the normal distribution of the variables. Based on normality status, independent-samples t-test or the Mann-Whitney U test were used to compare the treatment groups. Nominal variables were presented as counts and percentages, and Chi-square or Fischer's Exact test were used to test the differences. To test the change in BDI scores between different assessment points, the paired t-test was used to measure the change from one point to the other and the repeated measures analysis of variance (ANOVA) was used to assess the change over all three points. To assess the change of patients' distribution, the Wilcoxon signed ranks test was used to measure the change from one point to the other, and Friedman's test was used to assess the change over all three points.

\section{Results}

A total of 179 patients participated in the current study of which 119 were treated with isotretinoin and 60 were managed using other treatments (Retin-A and Tazorac). The mean age for all participants was $21.35 \pm$ 2.96 years and the majority of them were single (81.01\%) and females (62.01\%). About two-thirds (64.80\%) of the patients had a secondary school as their highest degree obtained, while about one-third (31.28\%) had university degrees and only $3.91 \%$ had diplomas. The baseline characteristics of both treatment groups were comparable, except for gender disparities (p-value < 0.001) (Table 1). 


\section{Cureus}

\begin{tabular}{|c|c|c|c|c|c|c|c|c|}
\hline \multirow{4}{*}{ Variables } & & \multicolumn{6}{|c|}{ Treatment } & \multirow{4}{*}{ P-value } \\
\hline & & \multirow{2}{*}{\multicolumn{2}{|c|}{$\begin{array}{l}\text { Isotretinoin } \\
(\mathrm{N}=119)\end{array}$}} & \multirow{2}{*}{\multicolumn{2}{|c|}{$\begin{array}{l}\text { Other treatments } \\
(\mathrm{N}=60)\end{array}$}} & \multirow{2}{*}{\multicolumn{2}{|c|}{ (N = 179) }} & \\
\hline & & & & & & & & \\
\hline & & $N$ & $\%$ & $\mathrm{~N}$ & $\%$ & $\mathrm{~N}$ & $\%$ & \\
\hline \multicolumn{2}{|l|}{ Age: mean (SD) } & \multicolumn{2}{|c|}{$21.45(3.01)$} & \multicolumn{2}{|c|}{$21.13(2.86)$} & \multicolumn{2}{|c|}{$21.35(2.96)$} & 0.561 \\
\hline \multirow{2}{*}{ Gender } & Female & 60 & 50.42 & 51 & 85.00 & 111 & 62.01 & \multirow{2}{*}{$<0.001^{*}$} \\
\hline & Male & 59 & 49.58 & 9 & 15.00 & 68 & 37.99 & \\
\hline \multirow{2}{*}{ Marital status } & Married & 25 & 21.01 & 9 & 15.00 & 34 & 18.99 & \multirow{2}{*}{0.666} \\
\hline & Single & 94 & 78.99 & 51 & 85.00 & 145 & 81.01 & \\
\hline \multirow{3}{*}{ Education } & Diploma & 4 & 3.36 & 3 & 5.00 & 7 & 3.91 & \multirow{3}{*}{0.546} \\
\hline & Secondary & 75 & 63.03 & 41 & 68.33 & 116 & 64.80 & \\
\hline & University & 40 & 33.61 & 16 & 26.67 & 56 & 31.28 & \\
\hline
\end{tabular}

\section{TABLE 1: Baseline Characteristics of the Included Patients}

*Statistically significant

$\mathrm{N}$ : numbers; SD: standard deviation

The mean BDI score at the baseline was $3.31 \pm 6.98$ for isotretinoin and $3.17 \pm 6.27$ for other treatments. Compared to the baseline, patients using the isotretinoin showed a significant reduction in depression scores at three months $(2.64 \pm 6.17$; $p$-value $<0.001)$, six months $(1.99 \pm 5.08$; $p$-value $<0.001)$, and across all follow-up points ( $p$-value $<0.001$ ). Similarly, there was a significant reduction in depression scores in patients that were managed with other treatments, including three months follow-up $(2.72 \pm 5.76$; $p$-value $<$ $0.001)$, six months follow-up $(2.47 \pm 5.32$; $p$-value $<0.001)$, and across all follow-up points ( $\mathrm{p}$-value $<0.001)$. However, there was no statistically significant difference when comparing the changes of the BDI score in isotretinoin and other treatment groups $(p$-value $=0.885)($ Table 2$)$.

\begin{tabular}{|c|c|c|c|c|c|c|c|c|c|c|}
\hline \multirow{3}{*}{ Treatment } & \multicolumn{10}{|c|}{ Beck Depression Inventory } \\
\hline & \multicolumn{2}{|c|}{ Baseline } & \multicolumn{2}{|c|}{3 months } & \multirow{2}{*}{$\begin{array}{l}\text { P-value }(0-3 \\
\text { months) } \Psi\end{array}$} & \multicolumn{2}{|c|}{6 months } & \multirow{2}{*}{$\begin{array}{l}\text { P-value (0-6 } \\
\text { months) } \Psi\end{array}$} & \multirow{2}{*}{$\begin{array}{l}\text { P-value }(0-3-6 \\
\text { months) } \dagger\end{array}$} & \multirow{2}{*}{$\begin{array}{l}\text { P-value (treatment } \\
\text { comparison) } \dagger\end{array}$} \\
\hline & Mean & SD & Mean & SD & & Mean & SD & & & \\
\hline $\begin{array}{l}\text { Isotretinoin }(N= \\
119)\end{array}$ & 3.31 & 6.98 & 2.64 & 6.17 & $<0.001^{*}$ & 1.99 & 5.08 & $<0.001^{*}$ & $<0.001^{*}$ & \multirow{2}{*}{0.885} \\
\hline $\begin{array}{l}\text { Other treatments }(\mathrm{N} \\
=60)\end{array}$ & 3.17 & 6.27 & 2.72 & 5.76 & $<0.001^{*}$ & 2.47 & 5.32 & $<0.001^{*}$ & $<0.001^{*}$ & \\
\hline
\end{tabular}

\section{TABLE 2: Changes in Depression Scores from Baseline and up to Six Months}

$\Psi$ Paired t-test

$†$ Repeated measures analysis of variance (ANOVA)

* Statistically significant

$\mathrm{N}$ : numbers; SD: standard deviation

Regarding depression categories, the majority of the patients were normal at baseline, whether in the isotretinoin group (91.60\%) or the other treatment group (91.67\%). Compared to the baseline, patients using isotretinoin showed a significant change in the distribution of depression categories at three months (pvalue $=0.011)$, six months $(p$-value $=0.010)$, and across all follow-up points $(p$-value $<0.001)$. Nevertheless, 
no similar significant changes were detected among the patients managed with other treatments, when comparing the baseline to three months follow-up ( -value $=0.157)$, six months follow-up ( -value $=0.157)$, and across all follow-up points (p-value $=0.333)($ Table 3$)$.

\begin{tabular}{|c|c|c|c|c|c|c|c|c|}
\hline \multirow{3}{*}{\multicolumn{2}{|c|}{ Depression Category }} & \multicolumn{6}{|c|}{ Treatment group } & \multirow{3}{*}{ P-value } \\
\hline & & \multicolumn{2}{|c|}{ Isotretinoin } & \multicolumn{2}{|c|}{ Other treatments } & \multicolumn{2}{|c|}{ Total } & \\
\hline & & $\mathrm{N}$ & $\%$ & $\mathrm{~N}$ & $\%$ & $\mathrm{~N}$ & $\%$ & \\
\hline \multirow{6}{*}{ BDI-baseline } & Normal & 109 & 91.60 & 55 & 91.67 & 164 & 91.62 & \multirow{6}{*}{0.978} \\
\hline & Mild depression & 3 & 2.52 & 2 & 3.33 & 5 & 2.79 & \\
\hline & Borderline depression & 1 & 0.84 & 1 & 1.67 & 2 & 1.12 & \\
\hline & Moderate depression & 2 & 1.68 & 1 & 1.67 & 3 & 1.68 & \\
\hline & Severe depression & 4 & 3.36 & 1 & 1.67 & 5 & 2.79 & \\
\hline & Extreme depression & 0 & 0.00 & 0 & 0.00 & 0 & 0.00 & \\
\hline \multirow{6}{*}{ BDI - 3 months } & Normal & 112 & 94.12 & 56 & 93.33 & 168 & 93.85 & \multirow{6}{*}{0.893} \\
\hline & Mild depression & 2 & 1.68 & 1 & 1.67 & 3 & 1.68 & \\
\hline & Borderline depression & 1 & 0.84 & 2 & 3.33 & 3 & 1.68 & \\
\hline & Moderate depression & 1 & 0.84 & 0 & 0.00 & 1 & 0.56 & \\
\hline & Severe depression & 3 & 2.52 & 1 & 1.67 & 4 & 2.23 & \\
\hline & Extreme depression & 0 & 0.00 & 0 & 0.00 & 0 & 0.00 & \\
\hline \multirow{6}{*}{ BDI-6 months } & Normal & 114 & 95.80 & 56 & 93.33 & 170 & 94.97 & \multirow{6}{*}{0.842} \\
\hline & Mild depression & 1 & 0.84 & 1 & 1.67 & 2 & 1.12 & \\
\hline & Borderline depression & 2 & 1.68 & 2 & 3.33 & 4 & 2.23 & \\
\hline & Moderate depression & 0 & 0.00 & 0 & 0.00 & 0 & 0.00 & \\
\hline & Severe depression & 2 & 1.68 & 1 & 1.67 & 3 & 1.68 & \\
\hline & Extreme depression & 0 & 0.00 & 0 & 0.00 & 0 & 0.00 & \\
\hline
\end{tabular}

TABLE 3: Categories of Depression Within the Study Population at Baseline and After Three and Six Months of Treatment

BDI: Beck Depression Inventory; N: numbers

\section{Discussion}

Evidence shows that developing depression as a side effect following isotretinoin administration is very common. Previous studies showed that this drug is fat-soluble and can easily pass the blood-brain barrier, affecting various parts of the central nervous system involving the dopaminergic receptors, leading to depression and mood abnormalities [14-16]. Since acne vulgaris usually occurs during adolescence, management of such events is essential to provide a better quality of life (QoL) for these patients. A previous systematic review reported that isotretinoin administration in acne patients was associated with the secondary development of depression in these patients [17]. On the other hand, our results showed that isotretinoin use was associated with a significant reduction in the BDI scores over all of the follow-up points. In a systematic review conducted by Huang et al., they reported that the pooled depression scores from the included studies significantly decreased within the first four months after initiation of treatment; however, the scores began to increase within the following months [18]. Among the included studies in the same review, the authors showed that four of them indicated that the depression scores increased within the first three to four months after treatment, while another two studies reported that the scores were significantly reduced six months after treatment initiation. Our results are also consistent with Webster et al. who reported that secondary depression symptoms resolved gradually even without stopping isotretinoin administration [19]. Another recent meta-analysis also showed that isotretinoin administration was associated with decreased depressive symptoms among patients that suffered from acne [20]. 
Many previous studies have suggested the association between isotretinoin administration and depression, especially in patients that already suffer from depression. A previous study from Jeddah, Saudi Arabia showed that the prevalence of depression in their population was $15.8 \%$ [21]. This prevalence rate can be similar to the prevalence rate of depression among the general population [11]. We also did not find a significant difference between the isotretinoin and other treatment groups regarding the mean BDI differences. Such results suggest that the treatment of acne vulgaris, whether by isotretinoin or other treatment modalities that were used in our population, is not associated with the development of depression secondary to drug administration. Our results indicate that isotretinoin use is significantly associated with reduced BDI scores in acne treatment. This is consistent with the previous randomized controlled trial by Suarez et al. who showed that the development of depression was associated with the presence of acne, irrespective of the applied treatment modality [22]. Consequently, it can be suggested that clinicians should be aware that acne patients may suffer from depression, irrespective of the applied management modality.

Our results also indicated that no depression category was significantly prevalent over the other, either at baseline, three months, or six months of follow-up. It can also be judged that depression relieves with time after isotretinoin administration. The risk of acne relapse after isotretinoin administration might also be a contributing factor to developing depressive symptoms. A previous Saudi study showed that, among the patients that administered isotretinoin, the acne relapse rate was $45.12 \%$ in these patients [23]. Shams et al. reported that females, obese, illiterate, poor, and with severe acne suffer from reduced QoL and usually need psychological counseling together with the specified acne medication [24]. This was also supported by Dreno et al. where they reported that patients with acne relapses usually suffer from reduced QoL and loss of productivity [25]. Consequently, all the previous findings suggest that depression development is not secondary to isotretinoin administration in acne patients.

Limitations to our study are the small sample size and the design of the study as proper sampling by randomization and blinding would be better. Besides, no laboratory data were assessed, and scoring was based on patients' self-reporting which may have impacted the results. Furthermore, the conflict of result with the literature can be attributed to response bias as patients might be thinking they will receive the treatment if if they responded in a certain way.

\section{Conclusions}

Our study showed no correlation between developing depression and isotretinoin administration during acne treatment. On the other hand, acne management, whether by isotretinoin or by other modalities, is significantly associated with reduced depression symptoms. The results of this study is in conflict with many previous studies done on isotretinoin and depression. Therefore, more studies studying the correlation in acne patients are needed among tertiary centers in Saudi Arabia.

\section{Additional Information}

\section{Disclosures}

Human subjects: Consent was obtained or waived by all participants in this study. Institutional Review Board, King Khalid University Hospital (KKUH) issued approval NA. Animal subjects: All authors have confirmed that this study did not involve animal subjects or tissue. Conflicts of interest: In compliance with the ICMJE uniform disclosure form, all authors declare the following: Payment/services info: All authors have declared that no financial support was received from any organization for the submitted work. Financial relationships: All authors have declared that they have no financial relationships at present or within the previous three years with any organizations that might have an interest in the submitted work. Other relationships: All authors have declared that there are no other relationships or activities that could appear to have influenced the submitted work.

\section{References}

1. Williams HC, Dellavalle RP, Garner S: Acne vulgaris. Lancet. 2012, 379:361-372. 10.1016/s01406736(11)60321-8

2. Katsambas AD, Stefanaki C, Cunliffe WJ: Guidelines for treating acne. Clin Dermatol. 2004, 22:439-444. 10.1016/j.clindermatol.2004.03.002

3. Dreno B, Poli F: Epidemiology of acne. Dermatology (Basel, Switzerland). 2003, 206:7-10. 10.1159/000067817

4. Thomas DR: Psychosocial effects of acne . J Cutan Med Surg. 2004, 8:3-5. 10.1007/s10227-004-0752-X

5. Saitta P, Keehan P, Yousif J, Way BV, Grekin S, Brancaccio R: An update on the presence of psychiatric comorbidities in acne patients, Part 2: depression, anxiety, and suicide. Cutis. 2011, 88:92-97.

6. James WD: Clinical practice. Acne. N Engl J Med. 2005, 352:1463-1472. 10.1056/NEJMcp033487

7. Dawson AL, Dellavalle RP: Acne vulgaris. BMJ. 2013, 346:f2634. 10.1136/bmj.f2634

8. Chivot M: Retinoid therapy for acne. A comparative review . Am J Clin Dermatol. 2005, 6:13-19. 10.2165/00128071-200506010-00002

9. Wessels F, Anderson AN, Kropman K: The cost-effectiveness of isotretinoin in the treatment of acne. Part 1. A meta-analysis of effectiveness literature. S Afr Med J. 1999, 89:780-784.

10. Brzezinski P, Borowska K, Chiriac A, Smigielski J: Adverse effects of isotretinoin: a large, retrospective 
review. Dermatologic therapy. 2017, 30:e12483. 10.1111/dth.12483

11. Borovaya A, Olisova O, Ruzicka T, Sárdy M: Does isotretinoin therapy of acne cure or cause depression? . Int J Dermatol. 2013, 52:1040-1052. 10.1111/ijd.12169

12. Wolverton SE, Harper JC: Important controversies associated with isotretinoin therapy for acne . Am J Clin Dermatol. 2013, 14:71-76. 10.1007/s40257-013-0014-z

13. Kontaxakis VP, Skourides D, Ferentinos P, Havaki-Kontaxaki BJ, Papadimitriou GN: Isotretinoin and psychopathology: a review. Ann Gen Psychiatry. 2009, 8:2. 10.1186/1744-859x-8-2

14. Diehl DJ, Gershon S: The role of dopamine in mood disorders . Compr Psychiatry. 1992, 33:115-120. 10.1016/0010-440x(92)90007-d

15. O'Reilly KC, Trent S, Bailey SI, Lane MA: 13-cis-retinoic acid alters intracellular serotonin, increases 5HT1A receptor, and serotonin reuptake transporter levels in vitro. Exp Biol Med (Maywood). 2007, 232:1195-1203. 10.3181/0703-rm-83

16. Bremner JD, McCaffery P: The neurobiology of retinoic acid in affective disorders . Prog Neuropsychopharmacol Biol Psychiatry. 2008, 32:315-331. 10.1016/j.pnpbp.2007.07.001

17. Bremner JD, Shearer KD, McCaffery PJ: Retinoic acid and affective disorders: the evidence for an association. J Clin Psychiatry. 2012, 73:37-50. 10.4088/JCP.10r05993

18. Huang YC, Cheng YC: Isotretinoin treatment for acne and risk of depression: a systematic review and metaanalysis. J Am Acad Dermatol. 2017, 76:1068-1076.e9. 10.1016/j.jaad.2016.12.028

19. Webster GF, Leyden JJ, Gross JA: Results of a phase III, double-blind, randomized, parallel-group, noninferiority study evaluating the safety and efficacy of isotretinoin-lidose in patients with severe recalcitrant nodular acne. J Drugs Dermatol. 2014, 13:665-670.

20. Li C, Chen J, Wang W, Ai M, Zhang Q, Kuang L: Use of isotretinoin and risk of depression in patients with acne: a systematic review and meta-analysis. BMJ Open. 2019, 9:e021549. 10.1136/bmjopen-2018-021549

21. Mleeh NT, Alshamrani HM, Basyouni RN, Alshehri KA, Algethami MR, Sehlo MG: Prevalence and predictors of depression among dermatology clinic patients in a teaching hospital, Jeddah, Saudi Arabia. J Family Med Prim Care. 2019, 8:2496-2501. 10.4103/jfmpc.jfmpc_399_19

22. Suarez B, Serrano A, Cova Y, Baptista T: Isotretinoin was not associated with depression or anxiety: a twelve-week study. World J Psychiatry. 2016, 6:136-142. 10.5498/wjp.v6.i1.136

23. Alshammari SA, Alamri Y, Alanazi AM, Almuhanna SA, Pinjabi L, Alsnaidi NA: Prevalence and associated risk factors of acne relapse among Saudi acne vulgaris patients using isotretinoin. Saudi Pharm J. 2020, 28:374-379. 10.1016/j.jsps.2020.01.019

24. Shams N, Niaz F, Zeeshan S, Ahmed S, Farhat S, Seetlani NK: Cardiff acne disability index based quality of life in acne patients, risk factors and associations. J Liaquat Uni Med Health Sci. 2018, 17:29-35. 10.22442/jlumhs.181710545

25. Dreno B, Bordet C, Seite S, Taieb C; 'Registre Acné' Dermatologists: Acne relapses: impact on quality of life and productivity. J Eur Acad Dermatol Venereol. 2019, 33:937-943. 10.1111/jdv.15419 